\begin{tabular}{|c|c|c|}
\hline $\begin{array}{l}\text { PKS } \\
\text { PUBLIC } \\
\text { KNOOLEDGE } \\
\text { PROJECT }\end{array}$ & $\begin{array}{c}\text { REVISTA DE GEOGRAFIA } \\
\text { (RECIFE) } \\
\text { http://www.revista.uffe.br/revistageografia }\end{array}$ & $\begin{array}{l}\text { OJS } \\
\frac{\text { OPEN }}{\text { JOUNAL }} \\
\text { SYSTEMS }\end{array}$ \\
\hline
\end{tabular}

\title{
ETNOGEOMORFOLOGIA SERTANEJA: SABERES TRADICIONAIS DA AGRICULTURA FAMILIAR SOBRE OS PROCESSOS MORFOESCULTURADORES DA PAISAGEM E O SEU USO E MANEJO DO SOLO NO MUNICÍPIO DE JARDIM - CE
}

\begin{abstract}
Maria Rayssa Vieira Antunes ${ }^{1}$, Simone Cardoso Ribeiro ${ }^{2}$
${ }^{1}$ Universidade Regional do Cariri. Email: rayssa.antunes@yahoo.com.br

${ }^{2}$ Docente da Universidade Regional do Cariri. Email: simone.ribeiro@urca.br

Artigo recebido em 08/12/2017 e aceito em 09/03/2018

RESUMO

A Etnogeomorfologia é uma vertente da Geomorfologia que busca identificar as percepções ambientais de cunho geomórfico advindas dos saberes vernaculares das comunidades que tem base de produção familiar. Esse trabalho objetiva analisar os etnoconhecimentos sertanejos do semiáriodo nordestino acerca dos processos morfoesculturadores que modelam a paisagem, como são classificadas as formas de relevo produzidas e como estes atores aplicam esses saberes no uso e manejo do solo. Inicialmente foi realizado o levantamento de dados geoambientais e posteriormente realizadas entrevistas com membros de três comunidades agropastoris do município de Jardim/Ceará. Foi feita a análise dos dados obtidos e constatado que eles têm um vasto conhecimento sobre os processos geomórficos exógenos, e usam esses saberes para adaptar as suas atividades no campo. Conclui-se que a Etnogeomorfologia pode assumir um papel importante nos projetos de ordenamento territorial, pois resgata conhecimentos tradicionais efetivamente utilizados pelos prncipais agentes de mudanças espaciais das áreas rurais sertanejas, os produtores familiares, podendo ainda ser relacionada com os conhecimentos acadêmicos buscando assim um melhor diálogo com estas comunidades em busca de um desenvolvimento local mais eficiente.
\end{abstract}

Palavras-chave: Etnociência; Geomorfologia; Comunidades Tradicionais.

\section{ETHNOGEOMORPHOLOGY FROM CAMP: TRADITIONAL KNOWLEDGE OF FAMILY AGRICULTURE ON THE MORFOESCULTURING PROCESSES OF THE LANDSCAPE AND THEIR USE AND MANAGEMENT OF SOIL IN THE MUNICIPALITY OF JARDIM - CE}

\begin{abstract}
Ethnogeomorphology is a Geomorphology strand that seeks to identify the geomorphic environmental perceptions derived from the vernacular knowledge of communities that have a family production base. This work aims to analyze the sertanejo ethno - cognitions of the northeastern semiarid about the morphosculture processes that model the landscape, how the forms of relief produced are classified and how these actors apply these knowledge in the use and management of the soil. Initially, geoenvironmental data were collected, and lates, interviews were carried out with members of three agropastoral communities in the municipality of Jardim / Ceará. The data obtained were analyzed and verified that they have a vast knowledge about exogenous geomorphic processes, and use these knowledge to adapt their activities in the field. It is concluded that the ethnogeomorphology can play an important role in territorial planning projects, as it rescues traditional knowledge effectively used by the main agents of spatial change in the rural areas of the country, the family producers, and may also be related to academic knowledge seeking so a better dialogue with these communities in search of a more efficient local development.
\end{abstract}

Key-words: Ethnoscience; Geomorphology; Traditional Communities. 


\section{INTRODUÇÃO}

O relevo é um componente da paisagem essencial para se compreender a organização social e a dinâmica ambiental, sendo a Geomorfologia uma ciência voltada para o estudo das formas do relevo visando investigar a sua origem e evolução, relacionando aos agentes que atuam diretamente ou indiretamente em seu modelado. O homem sertanejo também se torna um agente que modifica a paisagem, pois o mesmo atua e transforma o relevo com suas práticas agropastoris. A Etnogeomorfologia surge como uma vertente da Geomorfologia que busca identificar e sistematizar as taxonomias geomórficas produzidas por populações de cultura tradicional e vernacular e como elas usam estes saberes para o uso e manejo do solo, assim como relacionar estes conhecimentos com os de cunho acadêmico. Assim, visa desenvolver em comunidades rurais de cunho tradicional um melhor ordenamento local, tendo o conhecimento sobre as potencialidades e fragilidades da área como parâmetros que possibilitam melhores formas para o uso e manejo das áreas de produção agropastoris.

Os espaços semiáridos nordestinos têm maior tendência para desenvolver um quadro de fragilidade ambiental devido, principalmente, a seu déficit hídrico, e os projetos que são desenvolvidos nessas áreas não levam em consideração os saberes historicamente forjados sobre a dinâmica do uso e manejo dos recursos naturais, que são desenvolvidos pelas comunidades agropastoris de cultura tradicional. As politicas relacionadas a ações de gestão pública poderiam ser mais eficazes se feitas em conjunto com as comunidades, levando em consideração seus saberes sobre a dinâmica ambiental. O conhecimento que as comunidades tradicionais têm sobre seu meio é tida como essencial para compreender as realidades ambientais locais (RIBEIRO, 2012).

Para Costa (2011), essas comunidades, dotadas de cultura própria são vistas como etnocidades ecológicas, ou seja, retiram o seu sustento do meio em que vivem. Compreender o significado de relevo que as comunidades tradicionais têm pode levar a geomorfologia acadêmica a novas interpretações sobre os agentes etno-modeladores que produziram técnicas de manejo de atividades de subsistência ao longo do tempo. Assim, o objetivo desta pesquisa foi identificar como os produtores rurais familiares dos Sítios Cacimbas, Gravatá e Coitezero do Hipólito, no município de Jardim/CE, entendem e nomeiam os processos geomorfológicos e suas formas correlatas, como utilizam estas formas, e de que maneira esse conhecimento é utilizado na escolha do uso e manejo do solo. 


\section{MATERIAL E MÉTODOS}

\section{Área de estudo}

A metodologia ultilizada foi baseada nos estudos de Ribeiro (2012), a respeito da etnogeomorfologia das populações rurais na sub-bacia do rio Salgado/CE. Foi realizado inicialmente o levantamento bibliográfico para a construção do referencial teórico relacionado à Geomorfologia e Etnociências, voltado especialmente para a Etnoecologia, Etnopedologia, e, claro, Etnogeomorfologia.

Na pesquisa de campo executada em janeiro de 2017 foram realizadas entrevistas com os agricultores familiares no município de Jardim/CE, para a obtenção de dados relacionados às experiências cotidianas dos produtores rurais. A primeira comunidade entrevistada foi o Sítio Cacimbas com nove agricultores. A segunda comunidade foi o Sítio Gravatá com oito entrevistados e a terceira foi o Sítio Coitezero dos Hipólito com oito entrevistados. Os sítios foram escolhidos segundo a lógica da diferenciação de paisagens geomórficas, aliada às condições de acesso a eles.

A escolha dos entrevistados foi feita pelo método de indicação (Snowball Sampling), onde um agricultor já entrevistado indicava outro(a), e o limite qualitativo das entrevistas se dá quando as respostas estavam repetindo-se, bem como o nome dos agricultores para serem entrevistados - sendo esse o limite qualitativo para a coleta de dados segundo esse método. Foi utilizada durante as entrevistas, como ferramenta de auxilio, imagens de cicatrizes erosivas em seus diversos estágios, isso facilitou a identificação das feições sem haver interferência em sua taxonomia.

Ao decorrer da entrevista, com esse material impresso em mãos e com a visualização e identificação vernacular era indagado qual a nomenclatura dada ao processo erosivo e se eles sabiam quais as causas desses fenômenos. Em visita às áreas de produção e ao entorno das mesmas, foi visualizado na prática como os agricultores classificam os processos que atuam na modificação e reelaboração do relevo, que foram anteriormente identificados através das imagens, buscando observar na prática as etapas do destacamento, transporte e deposição do material erodido.

Ao fim das entrevistas, foram elaboradas tabelas contendo informações sobre o relevo, solo, erosões, movimentos gravitacionais de massa, uso e manejo e as taxonomias voltadas para a Etnogeomorfologia e, por fim, foi feita a comparação desses conhecimentos com os produzidos academicamente. 
Para auxiliar na compreensão dos etnoconhecimentos (em especial aqueles voltados para a relação solo-relevo) foi feito o levantamento das características geoambientais do município em questão, abordando as questões climáticas, classes gerais de solos, relevo e vegetação. Foram elaborados mapas digitais para identificar a área de pesquisa a partir de bases cartográficas disponibilizadas pelo IBGE (2015a). Em seguida, foi realizada a produção de perfis topograficos elaborados pelo 3D Path Profile/Line of Sight do software Global Mapper 6, usando como base as imagens SRTM ( MIRANDA, 2005).

\section{RESULTADOS E DISCUSSÕES}

Os Sítios Cacimbas, Gravatá e Coitezero dos Hipólito estão localizados no município de Jardim, no sul do Ceará (figura 1), situado nas coordenadas geográficas de 7²9'49.83' 'S e 39²1'35.40”O (Cacimbas); 7³0'50.92”S e 39²1'00.19”O (Gravatá); 7²0’30.75”S e 3907'48.80”'O (Coitezero dos Hipólito), como se pode observar na figura 2. O município possui população estimada em 27.076 habitantes que são distribuídos em uma área de $552,424 \mathrm{~km}^{2}$ (IBGE, 2017b). A faixa etária dos entrevistados varia entre 25 e 78 anos de idade.

Figura 1- Mapa de Localização do Município de Jardim/CE

\section{Localização da área de estudo}

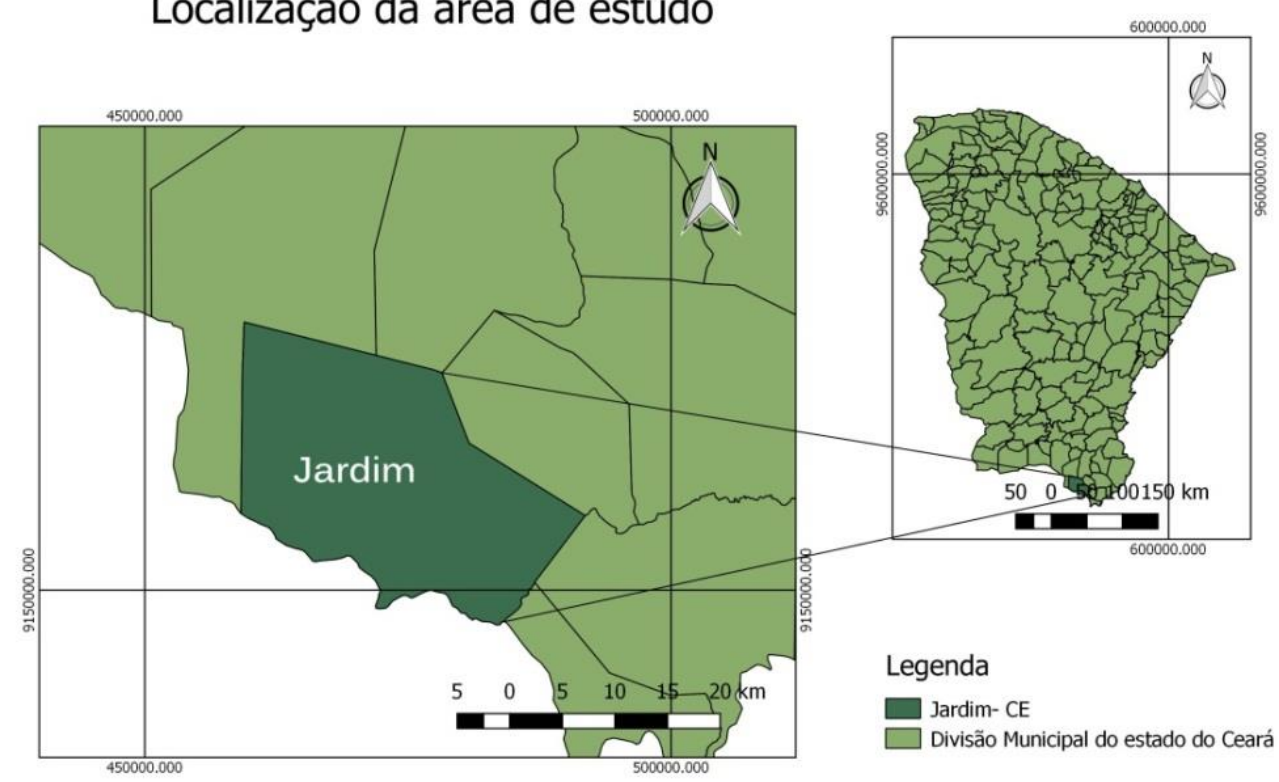

Fonte: Bases cartograficas disponibilizadas pelo IBGE 2010 Datum: Sigas 2000/ UTM zona $24 \mathrm{~s}$ Elaboração: Maria Rayssa Vieira Antunes 
Figura 2- Mapa de localização dos Sítios Cacimbas, Gravatá e Coitezeiro dos Hipólito.

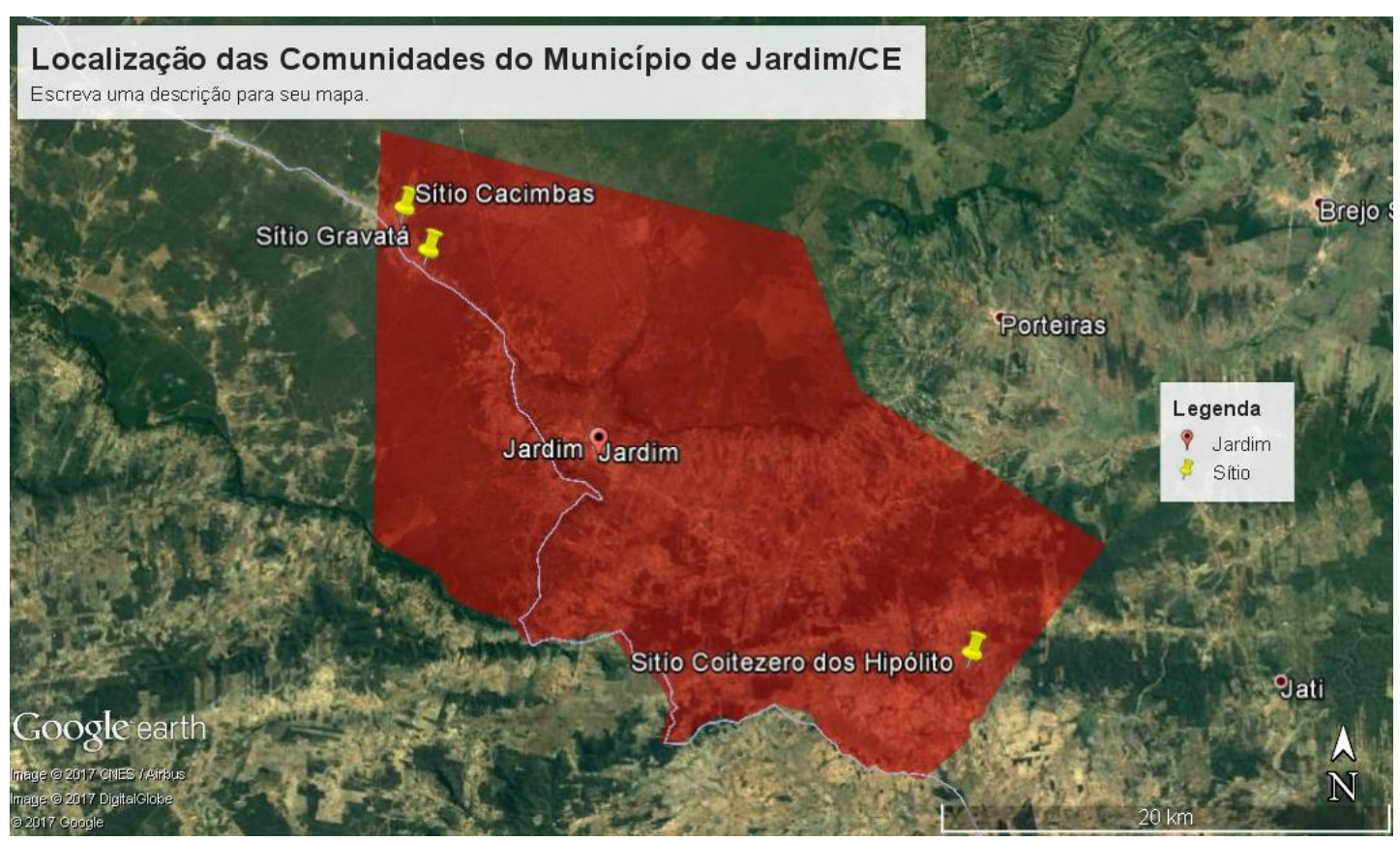

As comunidades em questão situam-se nas proximidades da Chapada do Araripe, com altimetrias que atingem cerca de 900 metros (MIRANDA 2005), apresentando em sua superfície Chapada tubuliforme seguida de áreas de encosta e área de várzea medianamente aplainadas. Sua litologia é composta por rochas areníticas em maior extensão territorial, conglomerados/silititos, alcalifeldspatos granitos/sienitos, e uma pequena parte com predominância de sedimentos argilo-arenosos, margas e micaxistos (FUNCEME, 2012).

As principais classes de solos que se desenvolvem nessa área são: Latossolo Amarelo Vermelho distrófico com presença de óxidos de ferro com textura argilosa e tem ocorrência predominante em relevo plano e suavemente ondulado. Argissolo com textura média argilosa/arenosa localizados em áreas onde o relevo é forte e ondulado, indica baixa a média fertilidade natural. Neossolo Litólico eutrófico e distrófico com textura média argilosa cascalhenta ou não, presença de relevo ondulado a montanhoso com substrato de arenito, micaxisto e gnaisse. Os Vertissolos tem presença de argila são presentes em relevos planos, suave ondulados e depressões locais. (FUNCEME, 2012)

A área, que faz parte da sub-bacia do rio Salgado, apresenta clima tropical semiárido e abriga vegetação do tipo Arbóreo-arbustiva, composta de várias espécies típicas do bioma Caatinga como o Cydonia oblonga (marmeleiro), Schinus terebinthifolius (Aroeira), Anadenanthera colubrina (angico) entre outras. 
Com base nos dados obtidos com os entrevistados, as comunidades são tradicionais, aplicam técnicas rudimentares com pouca interferência de maquinários. Alguns dos entrevistados são do município de Jardim e outros são de cidades próximas ou estados vizinhos, alegam terem ido para as respectivas comunidades para trabalharem com a terra, sejam arrendadas, como é o caso da maioria, ou proprietários das terras.

Das formas de relevo descritas pelos agricultores do Sítio Cacimbas, podemos destacar, referente às partes mais altas e aplainadas, as nomenclaturas de "chapada" e "serra", como ressalta um entrevistado: “o relevo aqui é pouco elevado porque serra é mais plana mesmo" . As áreas que tem um declive acentuado são chamadas de "lombadas", que sempre são seguidas de uma topografia mais rebaixada que é chamada de "baixa" ou "terras baixas" como é destacado na fala de um entrevistado: "Tem a parte baixa que é onde moreia, e tem parte alta que chama de chapada" (figuras 3 e 4 e quadro 1).

Figura 3- Perfil topográfico das unidades etnogeomorfológicas indicadas pelos produtores do Sítio Cacimba.

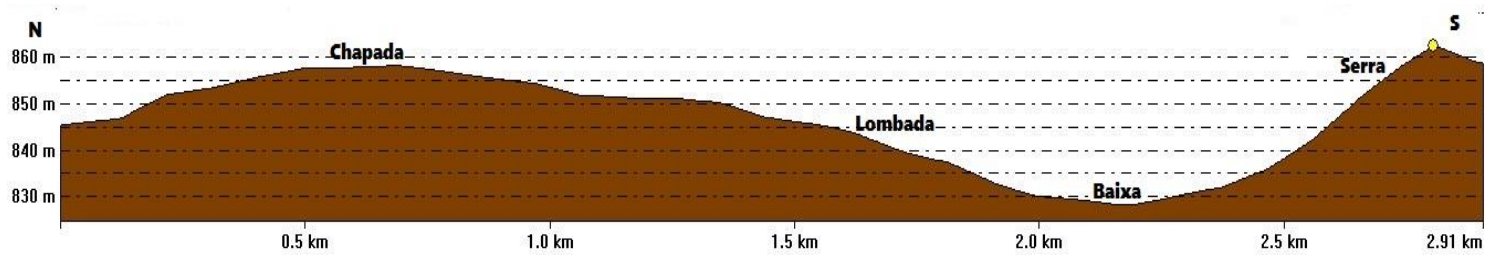

Figura 4- Perfil topográfico das unidades etnogeomorfológicas indicadas pelos produtores do Sítio Cacimba. Fonte: autoras, 2017

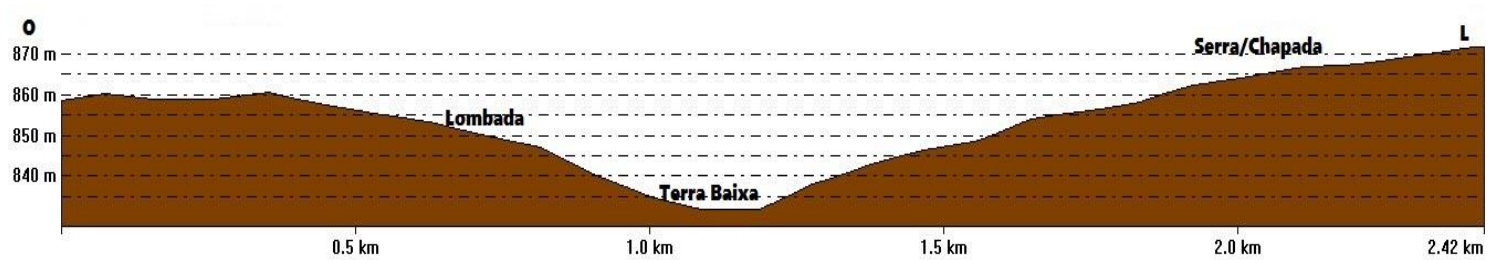

Os tipos de solos indicados pelos agricultores foram: "barro argiloso", "terra preta" ou "barro preto" e "terra branca" ou "terra ariúsca", "terra vermelha" ou "terra de carrasco”. Referente ao solo que tem melhor estrutura para se plantar, alguns consideram que a " terra preta" e" barro argiloso" é melhor ("Terra preta é boa pra plantar e a terra branca rejeito porque não dá”) (quadro 1).

Referente aos locais onde estes solos estão presentes um entrevistado ressalta: “ O baixo é melhor para plantar, a vegetação é sempre verdinha e a terra mais dura e com areia". 
No Sítio Gravatá foram identificados as áreas altas como "alto/alta" e "terra plana" como sempre são seguidas de áreas mais declivosas, identificadas como "acidentado" e as áreas rebaixadas que são comumente identificadas como "baixo", como também "terra plana" ou "terras baixas" sendo a forma que os agricultores identificaram como a mais presente na comunidade e que são melhor para o plantio, como afirma um entrevistado “terras planas, a melhor terra para plantar é em terra baixa porque é mais nutritiva” e outro, "Temos mais baixas, as terras altas são melhores para plantar capim e as baixa dá tudo" (figuras 5 e 6 e quadro 1 ).

Figura 5- Perfil topográfico das unidades etnogeomorfológicas indicadas pelos produtores do Sítio Gravatá.

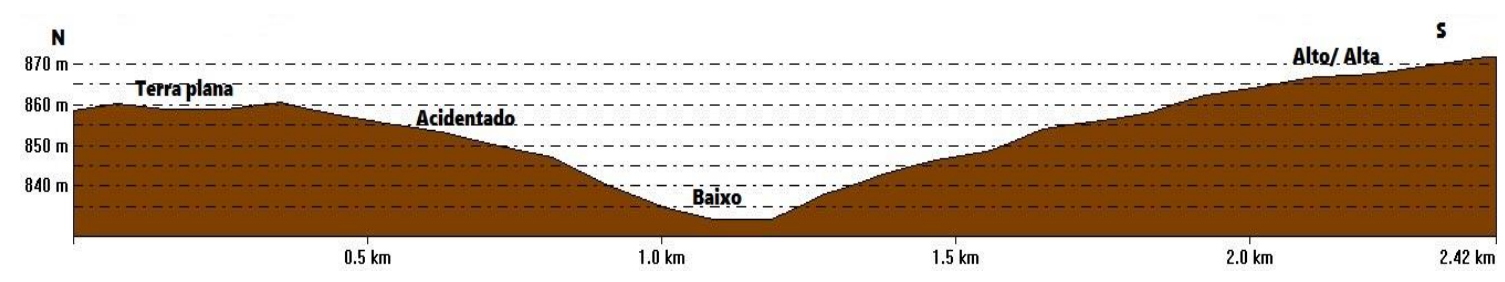

Figura 6- Perfil topográfico das unidades etnogeomorfológicas indicadas pelos produtores do Sítio Gravatá.

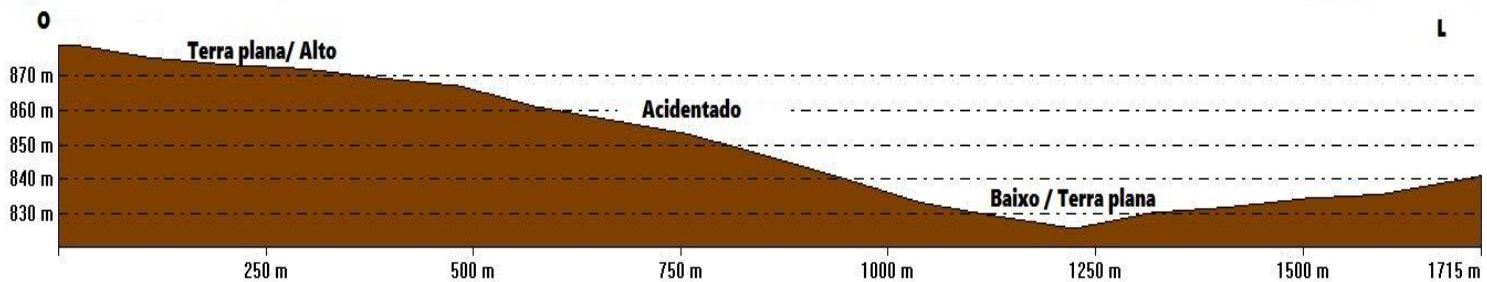

Os solos identificados pelos produtores foram: "terra preta”, "terra de barro", "terra morena", "terra barrenta", "massapê" ou "lajeiro" para solos mais escuros, "terra branca", terra de areia", "terra de encosta" são referente aos solos mais claros. O solo com coloração mais escura são melhores para o plantio, como pode se observar na fala do produtor: "A cor do solo, o mais escuro é melhor pra plantação, o mais branco pode não ser tanto quanto o escuro"(quadro 1).

Fazem relação de solo com o relevo, ressaltando que o solo é melhor para o plantio quando são localizados em áreas mais rebaixadas como pode observar na fala: "terras mais baixas são melhores para plantar, terra baixa são mais moles”.

Na comunidade do Coitezeiro dos Hipólito, localizada já em área do pediplano com colinas dissecadas (RIBEIRO, 2012), as áreas mais altas (relacionadas às colinas em dissecação) são classificadas como "ruins Relaciona as partes mais baixas a uma boa 
fertilidade - classificadas como "terra baixa", "baixo", "baixio" e "pé de serra" - $e$ isso se dá devido o acúmulo de sedimentos que são destacados das partes mais altas, transportados e depositados no relevo menos íngreme, como ressalta um entrevistado "Tem terras produtivas nas terras de baixio, pois é mais fácil de segurar a erosão. As terras de alto não são boas porque tem muitas pedras" (figuras 7 e 8 e quadro 1)" para o plantio, já que elas apresentam mais rochas e os solos pouco profundos e são identificadas comumente por "terra alta" e "serra".

Figura 7- Perfil topográfico das unidades etnogeomorfológicas indicadas pelos produtores do Sítio Coitezeiro dos Hipólito.

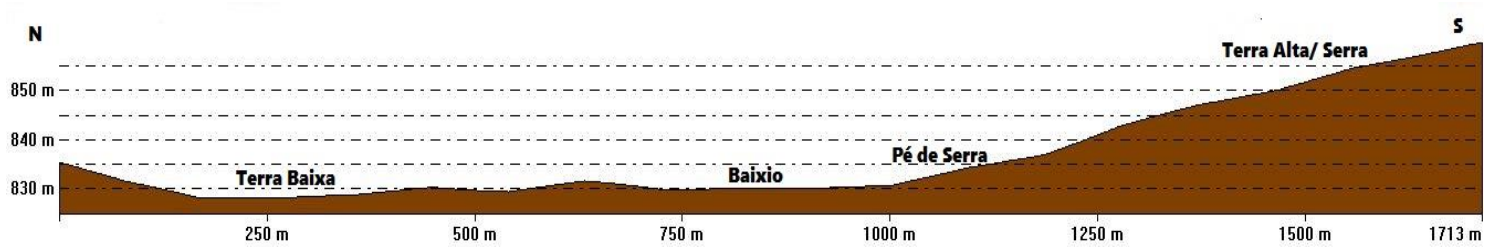

Figura 8- Perfil topográfico das unidades etnogeomorfológicas indicadas pelos produtores do Sítio Coitezeiro dos Hipólito.

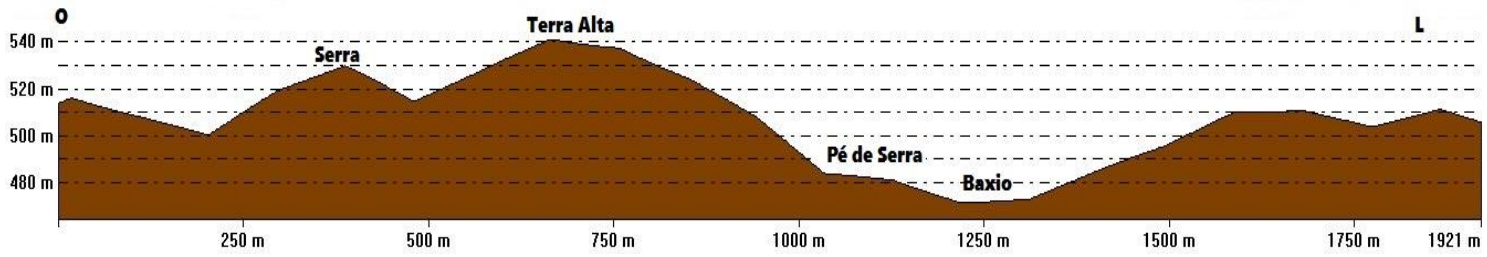

Os tipos de solos apontados seguindo a nomenclatura dos produtores foram: " terra branca”, terra de areia”, “terra ariúsca” ,para os solos mais claros , "barro vermelho”, "terra preta", “terra barro" e "massapê" para os que tem coloração mais escura (quadro 1).

A textura do solo também é identificada, como ressalta um agricultor: "Uma é mais enxugadeira que é a ariúsca, e a molhadeira que é barro e massapê. O barro e o massapê é melhor para o plantio porque segura mais o molhado”. Alegam que ás áreas que tem topografia mais baixa são melhores para o plantio: "A parte mais baixa tem mais vegetação. Sobre os solos, na baixa é o barro solto com arreia, na parte alta é pedra com terra encaliçada, que não entra arado”. 
Quadro 1 - Denominações locais para unidades básicas geomórficas e pedológicas identificadas pelos produtores rurais entrevistados

\begin{tabular}{|c|c|c|c|}
\hline $\begin{array}{r}\text { Sítios } \\
\text { Etnoconhecimentos }\end{array}$ & Cacimbas & Gravatá & $\begin{array}{l}\text { Coitezeiro dos } \\
\text { Hipólito }\end{array}$ \\
\hline \multirow{3}{*}{ Etnogeomorfologia } & $\begin{array}{l}\text { - "chapada"”"serra" } \\
\text { = áreas mais altas }\end{array}$ & $\begin{array}{l}\text {-"alto/alta" = áreas } \\
\text { mais altas }\end{array}$ & $\begin{array}{l}\text { - "terra } \\
\text { alta"/"serra" = } \\
\text { áreas mais altas }\end{array}$ \\
\hline & $\begin{array}{l}\text {-"lombadas" = } \\
\text { encosta mais } \\
\text { declivosas }\end{array}$ & $\begin{array}{l}\text { - "acidentado"= } \\
\text { encostas mais } \\
\text { declivosas }\end{array}$ & $\begin{array}{l}\text { (sem denominação } \\
\text { para encostas) }\end{array}$ \\
\hline & $\begin{array}{l}\text {-"baixa"/"terras } \\
\text { baixas" = áreas } \\
\text { rebaixadas }\end{array}$ & $\begin{array}{l}\text { - "baixo"/"terra } \\
\text { plana"/"terra baixa"= } \\
\text { áreas rebaixadas }\end{array}$ & $\begin{array}{l}\text { - "terras baixas"/ } \\
\text { "baixio"”/pé-de- } \\
\text { serra" =- áreas } \\
\text { rebaixadas }\end{array}$ \\
\hline \multirow{2}{*}{ Etnopedologia } & $\begin{array}{l}\text { "barro } \\
\text { argiloso"/"terra } \\
\text { preta"/"barro } \\
\text { preto"= solos } \\
\text { escuros e mais } \\
\text { férteis }\end{array}$ & $\begin{array}{l}\text { - "terra preta"/"terra } \\
\text { de barro"/"terra } \\
\text { morena"/"terra } \\
\text { barrenta"/"massapê" = } \\
\text { solos escuros }\end{array}$ & $\begin{array}{l}\text { - "barro vermelho"/" } \\
\text { terra preta"// terra } \\
\text { barro"/" massapê" } \\
=\text { solos escuros }\end{array}$ \\
\hline & $\begin{array}{l}\text { "terra } \\
\text { branca"/,terra } \\
\text { ariúsca"/,"terra } \\
\text { vermelha"/"terra de } \\
\text { carrasco"= solos } \\
\text { claros/avermelhados }\end{array}$ & $\begin{array}{l}\text { "'terra } \\
\text { branca"/"terra de } \\
\text { areia"/"terra de } \\
\text { encosta" = solos } \\
\text { claros }\end{array}$ & $\begin{array}{l}\text { - "terra branca"/", } \\
\text { terra de areia"/", } \\
\text { terra ariúsca"/" = } \\
\text { solos claros }\end{array}$ \\
\hline
\end{tabular}

O relato mais comum extraído das comunidades em questão foi sobre qual dos processos era mais recorrente. Sempre referiam à palavra "erosão da terra", e quando indagados sobre em que situação ocorre, sempre ressaltavam que se agravam ou aparecem juntamente com as chuvas, o que enquadra em "erosão pluvial/ pluvierosão" que é ocasionado pelas aguas das chuvas na superfície do relevo.

A erosão é a retirada química e/ou mecânica de partículas de solo que modela a paisagem, e os sertanejos identificam com mais facilidade a erosão linear em sulcos, decorrente do fluxo concentrado que é um processo que produz cicatrizes no solo, sendo denominadas de "caminho d'água", "levada" e "buraco". A partir dessas respostas notamos que eles não têm conhecimento sobre a erosão difusa já que a mesma não provoca cicatrizes na paisagem.

O fluxo linear pode originar microrravinas e ravinas, que são o estágio seguinte, decorrentes da maior concentração do fluxo de água que erode o solo. Os sertanejos fazem 
uso de termos como "Levada", "Lagoinha d'água"," Bojo das formigas", "Riacho", "Córrego levado" e "Vala" para nomear essas cicatrizes.

As ravinas que aumentam devido ao escoamento superficial concentrado, passam a fazer incisões mais profundas no solo e acarretam evolução dessa erosão, chegando ao estágio de voçorocamento. No etnoconhecimento dos entrevistados essas cicatrizes ganham outras nomenclaturas como "Riacho", "Grota", "Cratera", "Riacho Grande”, “ Bueiro”, "Buraco”, "Erosão" e "Sumidor de Água".

Já os Movimentos Gravitacionais de Massas, que consistem no deslocamento de massas do solo a partir da ação da gravidade, foram identificados pelos entrevistados, que os denominam de "Deslizamento", "Escorregão de Terra", "Barranco de Terra", "Desabamento" e "Arrastão".

Quadro 2 - Processos geomórficos exógenos - relação entre os conhecimentos acadêmicos e os etnoconhecimentos.

\begin{tabular}{|c|c|c|}
\hline & Acadêmico & Etnoconhecimentos \\
\hline \multirow{4}{*}{$\begin{array}{c}\mathbf{E} \\
\mathbf{R} \\
\mathbf{O} \\
\mathbf{S} \\
\tilde{\mathbf{A}} \\
\mathbf{O}\end{array}$} & Sulcos & Caminho d'água / Levada / Buraco \\
\hline & Microravinas & $\begin{array}{l}\text { Córrego / Bojo das Formigas / Lagoinha d'água / Rachadura / } \\
\text { Levada }\end{array}$ \\
\hline & Ravina & Vala / Levada / Riacho / Córrego levado \\
\hline & Voçoroca & $\begin{array}{l}\text { Riacho / Grota / Cratera/Caverna / Bueiro / Riacho Grande / Buraco } \\
\text { / Sumidor de água / Erosão }\end{array}$ \\
\hline \multicolumn{2}{|c|}{$\begin{array}{l}\text { MOVIMENTOS } \\
\text { GRAVITACIONAIS } \\
\text { DE MASSAS }\end{array}$} & $\begin{array}{l}\text { Deslizamento / Escorregão de terra / Barranco de terra / } \\
\text { Desabamento / Arrastão }\end{array}$ \\
\hline
\end{tabular}

O uso e ocupação do solo é o produto da reprodução social no plano do espaço, que é estabelecido pelas atividades no solo. Na zona rural do município de Jardim/CE, o uso e manejo do solo se dá pela moradia, produção agrícola e criatório de animais. Nesse espaço os agricultores sertanejos exercem sua atividade de cunho tradicional familiar e de subsistência.

As terras onde essas atividades são feitas em sua maioria são de posse dos agricultores, terras próprias. As áreas de plantio não são distantes das residências, algumas são no próprio terreno de moradia e outras nas proximidades. As três comunidades 
trabalhadas exercem produção de atividade agrícola semelhante, os produtos cultivados em comum são: feijão, milho, mandioca, fava, andu, melancia, arroz, fruticultura, tomate e alface.

A escolha do lugar para o plantio se dá através das terras que apresentem vegetação ou as áreas que tiveram alguns anos de descanso de plantil. O relevo também é um fator crucial para a escolha, e a preferência são para as áreas de topografia mais rebaixada como ressalta um entrevistado: "terras planas, a melhor terra para plantar é em terra baixa porque é mais nutritiva" e outro "Na terra do talhado não dá pra plantar nada porque tem muita declividade. A madeira é outra, de outro tipo em relação à terra plana”. Eles identificam que as áreas de topografia elevada têm solos mais duros, rasos e com presença de rochas.

A cor do solo também é importante, dão preferencia para os solos mais escuros e com presença de matéria orgânica ("A cor do solo, o mais escuro é melhor pra plantação, o mais branco pode não ser tanto quanto o escuro”) e falam que a diferença dos solos se dá pela adubagem - "Se diferencia pela adubagem. Terra preta é boa pra plantar e a terra branca rejeito porque não dá”. Isto indica que identificam a cor escura com o maior percentual de matéria orgânica contida no solo, e esta, com fertilidade.

Quando a produção diminui, eles utilizam como estratégia deixar a terra descansar por dois/quatro anos, mudam o cultivo ou simplesmente a adubam novamente, como se vê no relato de um agricultor:"Eu planto na mesma terra há 16 anos, sem adubo ela só aguenta dois anos e depois deixo mais dois anos ela descansando até criar mata".

Quando a vegetação está crescida, após o período de descanso, boa parte dos agricultores fazem queimadas em suas "roças". Retiram a cobertura vegetal para plantar novamente, chamam a vegetação de "capoeira". Posteriormente, limpam a terra ("Coivara"), juntam em um montinho e ateiam fogo, sendo esse processo comumente nomeado de "Broca".

Constatou-se que as repostas coletadas nas entrevistas foram bastante semelhantes, principalmente àquelas que fazem referência aos processos exógenos que modelam e elaboram o relevo bem como sobre o uso e manejo do solo, vale salientar que os métodos adotados por eles são proporcionais à necessidade da área em que produzem. 


\section{CONSIDERAÇÕES FINAIS}

O homem sertanejo, dotado de seu conhecimento vernacular utiliza-se de termos próprios para identificar as formas e os processos que esculpem a paisagem. São modos tradicionais muitas vezes hereditários de se tratar a terra, são saberes passados por gerações, aos quais a Academia nomeia de Etnoconhecimento. E esses etnoconhecimentos relacionados à visão que comunidades agro-pastoris compreendem as formas e processos de modelagem do relevo recebem o nome de Etnogeomorfologia, a qual foi largamente identificada através das entrevistas nas comunidades trabalhadas.

Com os dados obtidos ao longo da pesquisa foi possível concluir que as comunidades estudadas apresentam uma cultura muito próxima em relação ao conhecimento destes processos , relacionada especialmente às suas práticas agropastoris, as quais, com o passar das gerações foi sendo produzida. Utilizam conceitos e nomenclaturas semelhantes quanto às formas do relevo, assim como dos tipos de solos, focando especialmente na capacidade produtiva de ambos (relevos de "baixios" onde os sedimentos e umidade se concentram e produzem solos mais escuros, com maior percentual de matéria orgânica, assim como, de fertilidade). Identificam processos de esculturação da paisagem e têm nomenclaturas diferenciadas de acordo com os tamanhos/profundidades da cicatrizes produzidas, assim como diferenciam erosão de movimentos gravitacionais de massa, embora relacionem ambos às chuvas.

Assim, o agricultor do semiárido nordestino através das experiências na área em que vive e explora, compreende os potenciais e fragilidades da terra mostrando que a Etnogeomorfologia como um ramo das Etnociências pode assumir um papel de suma importância na identificação deste conhecimento podendo retornar como contribuição para as comunidades, se usada pelo poder público para um melhor diálogo com os principais atores das áreas rurias, suas comunidades agropastoris de produção familiar, para um melhor ordenamento local.

\section{REFERÊNCIAS}

COSTA, Lara Moutinho da. Cultura é Natureza - tribos urbanas e povos tradicionais. Rio de Janeiro: Garamond, 2011. Capítulos 8 e 9.

FUNCEME, Levantamento de Reconhecimento de Média Intensidade de Solos Mesorregião do Sul Cearense. Fundação Cearense de meteorologia e Recursos Hídricos, Fortaleza: 2012. 
IBGE - Instituto Brasileiro de Geografia e Estatística. Base de dados Cartográficos, 2015a. IBGE - Instituto Brasileiro de Geografia e Estatística. IBGE Cidades: Jardim/CE. Disponível em: http://cidades.ibge.gov.br/painel/painel.php?codmun=230710 Acesso em: 05/09/2017. IPECE. Instituto de Pesquisa e Estratégia Econômica do Ceará. Perfil Básico Municipal de Jardim Ceará 2015b. http://www.ipece.ce.gov.br/perfil_basico_municipal/2016/Jardim.pdfAcesso: 05/09/2017. MIRANDA, E. E. de; (Coord.). Brasil em Relevo. Campinas: Embrapaão há citação Monitoramento por Satélite, 2005. Disponível em: 〈http://www.relevobr.cnpm.embrapa.br〉. Acesso em: 12 Dez. 2016

RIBEIRO, S.C. Etnogeomorfologia Sertaneja: proposta metodológica para a classificação das paisagens da sub-bacia do rio Salgado/CE. Rio de Janeiro: UFRJ/PPGG, 2012. 278 p.(Tese de Doutorado) 